\title{
How Towels \\ Came to Matter \\ - on Discursive-Material Reconfigurings of Gender in Academia
}

\section{By Tine Damsholt}

Towels, humidity, teasing, bodies, sweat, marble, Orientalism, tone of voice, genitals - all these elements turned out to be involved in a specific material-discursive performing of gender. In a Turkish Hamam all these matters came to matter in a dynamic reconfiguring, where academic gender and academic bodies as material-discursive phenomena were destabilised and reconfigured in an ongoing process.

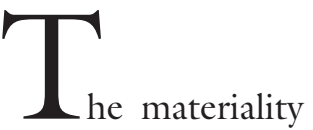
of the body and the materialisation of its gender have been somewhat challenging concepts for gender researchers over the past few decades. The biological body is often seen as a kind of threshold for social and discursive constructions. However, the performative strategy in the constructivist perception of gender, as led by Judith Butler, reintroduced the sexed body in all its materiality. But the question remains as to whether the analytical focus, even when a performative perspective is employed, should be limited to discourses about the body (Alaimo and Hekman 2008) plus the surface of the body and its coverings, such as clothing and make-up - if indeed the body is ever explicitly mentioned in the analyses. In this article, I argue that a much broader range of material-discursive practises must be included if we are to better understand how gender is enacted in all its concrete complexity. ${ }^{1}$

My analysis takes its starting point in a 
specific event that I experienced in the spring of 2002 in Istanbul while participating in a conference about 'Cultural encounters between East and West'. The conference was organised by employees at universities in Istanbul in joint cooperation with a Danish research group of which I was a member. ${ }^{2}$ Most of the participants were men, and the majority came from Denmark or Turkey, with a few speakers from the United Kingdom. However, nobody seemed to pay particular attention to gender - in principle, the few female participants (myself included) took part on equal terms with the men.

In Istanbul, the conference was held in a vacant bank building, where we sat in an open horseshoe formation in the middle of an atrium-like, columned marble hall. With the exception of the chairperson and the speakers, all of the participants were positioned in two rows facing each other without any hierarchical order. This emphasised that all of the participants were participating in the conference on an equal basis. We were dressed in classic conference attire: suits or respectable dresses. The fact that we were guests in a predominantly Islamic country meant that we were perhaps more formally dressed than is the case at academic conferences in Denmark. However, on the final morning of the conference, we moved to a different location to hear an analysis of the Italian-Turkish film "Hamam"; 3 the lecture itself would take place in a nearby hamam, or Turkish bath. In this new setting, that which Butler calls the "sexed body" was made visible in an entirely different way. At the same time, we as participants were all faced with the challenge of presenting or receiving an academic paper in a completely new material-discursive setting. Our presence in the hamam seemed to change how the academic gender was performed before, during and after the event. Academic gender was shown to be a highly heterogeneous phenomenon, which was not only related to the partici- pants' perceptions of gender, but also to our bodies and the physical materiality of our surroundings.

The term 'academic gender' refers to the act of downplaying differences between the sexes that is typical in academic contexts, according to Danish psychologist Dorthe Marie Søndergaard, who has studied how gender unfolds within academic culture in Denmark, based on Butler's performative approach (Søndergaard 1996). We in the aforementioned research group performed such a local version of gender, which could be called 'the stabilised academic gender'. The significance of the body was stabilised in the research group through particular roles and expectations. Our bodies were disciplined and partially veiled by clothing, which made it easier to deal with the sexed bodies in an academic context. Thus, the body and its gender markers were not the basis for how we acted as academics. As in most other similar situations, an implicit agreement was established regarding the centrality of professional and scientific matters; gender should not have any relevance to our seriousness or mutual recognition. In this way, the body was inscribed in an ideal of gender equality, in which we resisted any asymmetry between the genders. However, this stabilisation of gender and the idea of the body as subordinate to the academic proved to be dependent on the material situatedness.

In the following, I argue that the specific material situation or setting where gender is performed is an important element that plays an active role in the dynamic reconfigurings of gender; that is, how gender can be done, and how the body is involved in specific relations and stabilisations. Here, I examine the heterogeneous versions of ourselves that we were doing during the conference in Istanbul by using a kind of autoethnography, an analytic account of my own situated experience (Ellingson and Ellis 2008). Through a 'thick' description of the concrete actions - what happened, and 
how I experienced things at the time - I discuss how this event can be understood in its complexity using analytical approaches that focus on discourse and materiality. In this text, I attempt to reproduce the physical awkwardness of the experience in the hamam. Portraying the performed self, I try to re-enact an embodied experience for the reader. Of course, this is a very subjective account, as I have not systematically interviewed the other participants about their experiences. ${ }^{4}$ But as argued (e.g., Ellis, Adams and Bochner 2011), the focus of generalisability in auto-ethnography moves from respondents to readers, and to the question of whether the narrative and analysis speak to them. In this way, I aim to bring to light the wealth of material-discursive details and elements - such as space, humidity, teasing, towels, bodies, sweat, tone of voice, and so on - involved in 'doing' a specific version of gender. The main point made in this empirical example is that it is precisely within this material-discursive concreteness - including the bodily and spatial concreteness - that gender occurs, or is 'done'.

\section{BODIES THAT MATTER}

The idea that a paper on the Italian-Turkish film "Hamam" 5 should be presented in an actual hamam probably started off as a joke that later turned into reality, perhaps in part because a hamam visit is a required component of any tourist's trip to Istanbul. For a thousand years, Istanbul has been the West's doorway to the Orient - with all of the associations that this has conjured up over time (Said 1995 [1978]). In Turkey, hamams are normally divided into genderspecific bathing days, but our visit had to be arranged as a so-called 'mixed hamam'. This hybrid was not created on our behalf, but is practised in special hamams for Western tourists. A gender-segregated hamam would not have made sense for the aforementioned stabilisation of the academic gender in our group, where gender clearly should not play any role, and where one's relationships should only be determined by academic considerations (Søndergaard 1996). In Danish academia, gender should ideally be regarded as a long-closed chapter. Therefore, we Danes did not have any problem going to a mixed hamam, but instead considered the trip to be something that could be easily reconciled with the stabilised academic gender. 6

However, this was not the case for our Turkish host. He was graciousness personified, and committed in every sense to not offending anyone's cultural preferences. He was clearly worried about the female participants' reservations when he was asked to arrange a mixed hamam, and he repeatedly asked me (and all the female Danish participants $^{7}$ ) whether it was alright for us. I answered again and again that it was no big deal, and that we women could simply use more towels, ${ }^{8}$ etc. That is, I insisted on including the hamam in a Danish, egalitarian version of academic gender. And on the whole, the number of towels that each participant would be given became a standing joke among the Danish participants. But just as this joke was a way to 'enact' or do our 'Danish, completely relaxed' attitude towards gender and nudity, the constant joking was also a way in which the gender differences between participants were enacted in a new way; the number of towels became a materialisation of the gender differences between us.

It could be said that the friendly joking about the number of towels was also a subtle way to test ${ }^{9}$ the female members of the group. If we wanted to be 'one of the boys' on equal academic footing with the men, we should be able to participate equally in all of the same activities that they did. We had to demonstrate our Western idea of emancipation in the face of a non-egalitarian perception of gender by not being more shy or modest than the men. The teasing had a slightly risqué undertone. The fact 
that all of the participants had, of course, read Edward Said's canonical analysis of Orientalism (1995 [1978]) did not reduce the risqué connotations - on the contrary, it seemed to intensify them. ${ }^{10}$ Both the sensual dimensions of Orientalism and Said's deconstruction of them were an undercurrent of the teasing. The fact that we had read Said 'made' us into an academic and gender-equal version: emancipated from and raised above Western discourses about the East, as well as the East's gender-segregated discourses about the body. We were cheerfully elevated above it all. In this way, Said's analyses became one of the heterogeneous elements that was stabilised in our pre-understanding of the hamam situation. This understanding did not take into consideration the decisive significance of the body or the material situation - which is completely in line with the often symptomatic absence of materiality in discourse analyses (Barad 2007).

Several researchers have specifically criticised the absence of materiality in Butler's performative approach. Karen Barad also takes her point of departure in a critique of Butler; although Butler reworks the notion of matter as a process of materialisation, matter is re-inscribed as "a passive product of discursive practices rather than an active agent participating in the very process of materialization" (Barad 2003: 821) and is limited to the "construction of the contours of the human body" (2003: 822). In contrast to this, Barad's theory allows the notion of materialisation to be reworked in order to acknowledge the more complex entanglement of discursive practises and material phenomena that I describe in this article.

Barad argues that phenomena come to matter through specific intra-actions, and that a differential sense of being is enacted in the ongoing ebb and flow of agency. In these ongoing intra-actions, properties are stabilised and destabilised. The stabilisation of one phenomenon is the destabilisation of another. As one thing is brought to the front, something else is pushed back or excluded. In the context of the conference, the constant teasing prompted me to feel that my gender was suddenly being overexposed; that I was suddenly being classified more as a 'woman' and as a sexed body than as a conference participant or a research-group member on equal footing with the men. The constant talk about the differences between the sexed bodies threatened to destabilise the perception of what gender should mean and what it actually meant - a perception that I had helped to negotiate, stabilise and perform during the preceding year of the research group's work.

The bodies of the conference participants - and in particular, the type of genitals they possessed - became part of reconfiguring our genders. The fragmentation and compartmentalisation of the sexed body and its reduction to specific, named parts (Butler 1990: 114) was pivotal in this reconfiguring. I felt that my breasts which were the reason I needed two towels, in contrast to the male participants who only needed one around their waists - became that which was most prominent or significant about me. The relevance of my intellectual and research-related interests and potential had decreased; I was now primarily reconfigured as a natural body with a sex.

However, this experience of a sudden 'sexualisation' or the 'tacking on' of gender, which had previously been less visible, did not compel the female participants to cancel the hamam visit. We briefly spoke about it the evening before, practically reconfirming with each other that it really was not a problem' for an open-minded Dane. After all, we would not be any more naked than if we were in a swimming pool or on the beach, and that usually did not bother us. And this was indeed true. However, the point is that the sexed body did not become more prominent simply be- 
cause it became visible. On the contrary, it became apparent that how the body was covered - and the physical locality in which this covering took place - imbued the sexed body with increased significance.

\section{THE CUNNING OF MATERIALITY}

When we arrived at the hamam, we first entered a large anteroom that was furnished in classic Turkish style. Around the sides of the room, there was a raised balcony made from dark wood, with small changing rooms that had doors facing out to the balcony and the central space. In this area, six male staff members walked around, dressed in t-shirts, loincloths and bathing sandals, and our Turkish host began to negotiate with them. The staff's gender tends to be the same as that of the guests, but in the mixed hamam, the staff's gender was the same as only the male participants, and this contributed to configuring the female participants as a slight anomaly.

From the moment we arrived, this cool entrance hall, the staff and the interior generated automatic gender segregation. As such, the hamam functioned as an apparatus in Barad's sense:

...apparatuses are dynamic (re)configurings of the world, specific agential practices/intra-actions/performances through which specific exclusionary boundaries are enacted (2003: 816).

In the hamam, new boundaries were enacted that divided the group of researchers into two gendered categories: we four female participants gathered in a marginal position near the entrance at the boundary of the physical 'outdoors', whereas the men (12 to 15 in all) 'bravely' moved into the middle of the room and gathered around our Turkish host.

The hamam employees conferred for a long time, and it dawned on us that there was a problem with where the women should change clothes because there was a glass section in the upper part of the changing-room doors. These cubicles were designed to conceal genitals from other people's view and preserve male modesty, but they were insufficient for a woman to change in without exposing her breasts. The material design turned the female participants into a problem because we were unable to conform to the usual standardised changing practises. As this discussion continued, some staff started to distribute towels to the men, who spread out into the cubicles on the balcony, while other employees began to establish a modest changing room for the female participants. This involved a slightly haphazard hanging of towels over the windows of a large square cubicle, located inside the anteroom on the ground floor. Usually, this was the employees' room, from where the central room could be observed. The hideout that we women were given was particularly visible and somewhat attention-grabbing, precisely because the haphazardly covered windows appeared as an anomaly and became an apparatus that configured the women as an anomaly. Long after the men had finished changing and were starting to come out of their cubicles, we women finally got into our changing room, equipped with two towels each.

In her analysis "on being allergic to onions" (1991), Susan Leigh Star argues that every standardised activity is based on exclusion. It is arranged as though it is based on a universal consumer, but as soon as there is a user who does not correspond to this standard, the service becomes much more cumbersome and slow. In Star's case, this applied to ordering a burger without onions, and for us women in the hamam, it was our need for a changing room designed for people with gender markers above their waists. Star's point is that there are always people who fall outside of standardised categories, and therefore, every successful network always marginalises 
someone; she argues that the analysis should take its point of departure here.11 In the hamam, we women were made into a marginalised version that was materialised by our special changing room. At the same time, we were given an analytical head start, as this version made visible the relationships in which our (different versions of) academic selves were configured at the conference - both inside and outside the hamam setting.

When we four Danish women were alone in our changing room, we started to get undressed in order to put on the obligatory hamam attire: long, roughly woven, cotton garments with a red-and-orange checked pattern - called towels here since they are used as clothing/coverings in the hamam as well as to dry oneself. We briefly discussed whether we should keep our panties on, but one of us led the way and took hers off, referring to the Nordic sauna tradition; in these countries, a woman would always take them off. Keeping one's underwear on in the bathhouse seemed to conflict with the hygiene discourse that is embedded in the cultural history of bathing. In this sense, cultural history was a part of the material-discursive entanglement of the concrete doing. Barad argues that different apparatuses effectuate different cuts and draw different distinctions that delineate the 'measured object' (2003: 816). The hamam as a material-discursive apparatus drew new distinctions and delineated academic bodies as gendered phenomena.

However, our Danish cultural-historical inheritance failed to provide us with the skills for how to position the two narrow towels on our bodies, in part because they were very different from the terrycloth towels we were used to dealing with. Giggling, we tried to tie the towels in various ways so they were 'secure' (that is, neither slipped nor fell off) without looking too 'clumsy'. We also talked about our makeup, which might start to run. Gender could not be eliminated, and we did not wish to look unattractive either. In any case, I had these considerations, and even though I had been annoyed by the preoccupation with my sexed body, I had no desire to desexualise myself by entering the hamam with a completely disguised body or looking like an unattractive lump. I would only be a subject ${ }^{12}$ in the academic space that we would attempt to maintain in the hamam through the regulating matrix of gender.

These opposing strategies could be characterised as an 'ontological choreography'. In a study of women undergoing fertility treatment, Charis Cussins makes the point that objectification is only antithetical to personhood in certain circumstances, and she argues for a notion of agency not opposed by but pursued in objectification. She shows how women in the fertility clinic objectified themselves in different treatment practises in order to achieve a particular type of subjectivity: 'the pregnant woman'. This constant shift between the subject and object positions is called an "ontological choreography" (Cussins 1996). The term captures the logic of the opposing strategies of my own practise in the hamam; there, I subjugated myself to the heterosexual matrix, which made me into a subject only as a gendered being. By tying my towels so that they simultaneously concealed that which had to be hidden specifically, my skin from the armpit down to just above the knee - and did not conceal that which should be on show: a relatively slim female body with a certain measure of bust, waist and hips. I subjectified myself by objectifying myself - by emphasising my female gender markers in the concrete form that the two roughly woven towels allowed. As stiff as the towels were after having been repeatedly wet and dried, the material-discursive possibilities were somewhat limited.

The ontological choreography that I undertook in the hamam consisted of simultaneously attempting to do two versions of 
myself, between different cuts: as both object and subject at the same time; and as both an attractive female body and as a research colleague on the same level as the men at the same time. The ontological choreography was an attempt to 'dance' between these two versions and cuts - to tie them together so that they did not exclude one another, but instead became entangled. The bodily choreography I performed involved simultaneously covering and revealing certain body parts and certain aspects of my intellect. A multiple gender was produced through the agential intraactions of multiple apparatuses of bodily production.

\section{VERSIONS, CUTS AND THE RESISTANCE OF MATERIALITY}

When I stepped out of the changing room ready to do at least two versions of myself, I went from the cool anteroom through a smaller space and into the actual hamam, of which the male participants had already taken possession. They were either in the shower rooms or sitting in a sauna-like room. I immediately avoided the small sauna's heat - mostly to ease gently into the bodily community we were now going to enact, but especially because, through the glass, one could discern that a physically close homo-social community had been established there. Here, I as a woman would have been totally misplaced. It would be like stepping into a men's locker room: a forbidden area for any woman because it would dismantle any smooth stabilisation of gender. Therefore, like the other women, I sat down in the hamam's central space, the walls of which were covered with gray marble tiles, and where daylight seeped in through the dome's small stained-glass windows. There was a hexagonal marble platform in the middle of the central space, and other platforms in the four corners of the room. The most pervasive element was the moisture: steam was visible on the walls, and the sound of dripping or splashing water that came from the smaller space with the showers was a continuous 'soundscape'.

Eventually, we all gathered in the central space and spread ourselves around on the marble benches; the speaker started off standing in the middle of the raised hexagon. However, his voice rang out too strongly, and the sound jumped around and against the wet marble. This meant that we had to instead gather in two of the four corner niches; the space's acoustics demanded much more physical proximity between us than in the bank, where the earlier sessions of the conference were held. We got close to each other's skin and sweat, and a new, somewhat awkward bodily intimacy was established as the speaker began his lecture.

Here, seated close together and with an academic analysis being read aloud, the conference's academic-apparatus was partially re-established. We became calm and listened intensely, but even though marble dominated the design of both the bank and the hamam, there were big differences. The academic gender's invisibility could not simply be restored. The presence of physical bodies disturbed and undermined the stable configuring of gender and academics that we had done in the bank and in the conference's other, more traditional material surroundings. The cuts of the hamamapparatus produced new gendered bodies that could not be ignored - they were 'too noisy' in all their materiality and insistent character. We peeked discreetly at each other's bodies: shape, hairiness, rolls of fat, the flesh's looseness and colour. In contrast to our daily and more individual clothing, the uniform covering of orange-checked towels emphasised each body's unique outlines and forms. The hamam-apparatus of bodily production drew new boundaries.

The academic embodiment had to be done in completely different ways in the hamam's hot and humid marble landscape 
than in the bank's corresponding coolness. The point is not just that the heat made a difference; we had been to other sessions at the conference with high heat. There was not one single element that made the difference. The difference was made by the many material-discursive elements that comprised the specific relation, and which were intertwined in the hamam situation. In other words, the material-discursive setting was decisive for the configurings of gender and academics in which we could enact ourselves.

In many ways, the hamam's central room resisted becoming a conference space or conference-apparatus. Here, one can speak of material or distributed 'agency'. The first form of resistance was quite simply the heat that melted every attempt at full concentration. Our ability to focus ran out of us along with the sweat from our bodies. However, plastic bottles of cold spring water were brought in, which helped. The next attack on the conference-apparatus of our gathering was that one of the hamam's employees came into the middle of the lecture and rolled out a cushion, preparing to give us massages. We told him that we were not there for massages. Slightly offended, he rolled up his cushion and left the space; the presentation of the paper then continued.

But eventually the third form of resistance began, and this time nothing could be done. The 'paper' that was being presented physically consisted of a manuscript printed on plain white paper with handwritten notes. Unfortunately, the hamam's high humidity made the paper gradually disintegrate; at first, it was only that the individual pages were difficult to separate from each other. But soon the academic 'paper' dissolved in the literal sense, and a full academic discussion was sacrificed on the 'altar of heat and humidity'. At that point, the strict conference-apparatus that we had fought to re-establish was also dissolved by general hilarity. The hamam-ap- paratus was re-instated, and we behaved as regular bath guests for the remainder of our visit.

The corporality in the hamam also challenged several of the male participants, which one of them brought to my attention in a shared reflection about the event that evening. "One day, a famous professor and body researcher; the next, just a short little man with a too-big belly", he said about what he, in the hamam, had experienced as his own precipitous decline in prestige. Among the men, the nearly naked bodies in the hamam appeared to establish other hierarchical logics than skills in English, titles, celebrity, etc., had established the previous days. The hamam-apparatus brought about new boundaries and cuts of masculinity in academia.

These new and more complex versions of femininity and masculinity were included and done in a single configuration that entangled many material-discursive elements: architecture, marble, moisture and heat went along with us and the versions of ourselves (academic or otherwise) that we did. Likewise present were our more or less Orientalist-inspired discursive understandings of what a Turkish bath was. Thus, it was not any single element - such as we participants, our intentions nor the hamam itself - that made the situation. The situated phenomenon was material-discursive, entangled by all of these elements as well as the cultural-historical practises inscribed in materiality and our preconceptions.

Thus, the new phenomenon in which we were enacted cannot simply be reduced to the fact that we were more naked or unclothed than we were in the bank's cool interior. This is a matter of 'situated undress', a new differentiating cut that gave very specific situated experiences and insights, and which shaped a certain reconfiguring of gender. The situated enactment of being undressed was done in a different way by every single participant; thus, we human participants and the materiality were co- $^{-}$ 
constituting elements of the hamam as an apparatus.

\section{MULTIPLE BODIES AND SELVES}

Our bodies had no inherent essence but were simultaneously enacted and produced in different apparatuses - they were multiple. They were cut as part of different phenomena according to whether they were enacted as either a discrete 'appendage' to a bright academic paper in a cool bank, or enacted as more undressed, wrapped in uniform loincloths and sweating their way through an academic lecture inside a hot hamam - a material-discursive phenomenon. These specific versions or materialisations of body and gender were not essential nor final, but always part of open-ended and dynamic reconfigurings of the world.

In the aforementioned article by Star, she writes about "multiple selves" and "multiple memberships" that arise from the many communities of practise in which we exist. This dimension is radicalised here by my claim that we did different versions of ourselves within the same academic community of practise. What I have emphasised is the significance of materiality and apparatus. It is clear that we were different in the hamam - with towels wrapped around us and sweat running down our backs - than we were in the cool bank. As in Barad's article, however, a central point is that the different apparatuses of bodily production had no inherent "outside" beyond boundaries (2003: 816); they were not separated, but rather entangled, ongoing and openended practises.

When we were finished in the bathhouse, we went back to our separate changing rooms. I briefly glanced in a little mirror on the wall and laughed to myself at the sight of my mascara, which was in complete disarray. One of the versions I had tried to perform had also literally dissolved and run down my cheeks. After we dressed, all of the participants met outside the hamam. A certain shyness was there between us now, dressed in versions of ourselves that resembled the pre-hamam situation, but we were a little hesitant to re-establish or re-stabilise our old relationships and versions.

The fact that relationships between the genders in an academic context are complex can hardly come as a surprise to anyone. In Istanbul, perceptions of the body which had been stabilised by our research group as having an academic-neutral gender - became temporarily dissolved in the hot, damp hamam. One could say that the hamam-apparatus revealed that the academic ideal of gender equality is just one particular cut or stabilisation; a stabilisation that can be easily destabilised, and which was re-stabilised and re-formed by the hamam's insistent corporality and our materialisation in new configurings. After the hamam visit, we sought to perform the academic gender in new configurings that could accommodate both the bank-apparatus and the hamam-apparatus cuts, rather than simply re-establishing the bank-apparatus by marginalising the hamam-apparatus cuts.

Of course, these insights about the complexity of the 'work' of doing gender are not limited to a Turkish bath, where the number of towels came to matter. A range of components could be added to the performative understanding of gender with which I began this article, because the academic gender - in our daily lives at the university as well as at the hamam - is a material-discursive apparatus that stabilises the configurings. Butler's heterosexual matrix must constantly be repeated, materialised or unfolded, or else the performativity as 'iterative citationality' collapses (Barad 2007: 57, 63). However, the reiteration is neither unambiguous nor predetermined. We all have to improvise, and this means that the details are crucial - in our everyday academic lives as well.

In this article, I have tried to illustrate how matter comes to matter, and how tow- 
els came to matter at a hamam in Istanbul. "Apparatuses are material (re)configurings/discursive practises that produce material phenomena in their discursively differentiated becoming", states Barad (2003: 820 ). In the hamam and afterwards, academic gender and academic bodies as material-discursive phenomena were destabilised and reconfigured in ongoing processes. The multiple selves we enacted during the conference in Istanbul could be regarded as specific (re)configurings. But they may also be seen as entanglements, and more generally as components of one long ontological choreography with ever-changing scenery; a choreography that ensures the stabilisation of the academic gender, despite its momentary dissolution in the Turkish bath. Thus, the differential sense of being and the doing of gender are enacted in an ongoing ebb and flow of discursive and material agency.

\section{Notes}

1. I wish to thank my colleagues Dorthe Gert Simonsen, Marie Sandberg, and Morten Krogh Petersen for their helpful comments on earlier versions of this analysis, and Amy Clotworthy and Lucinda Ellis for qualified translation.

2 . The project group consisted of eight male and three female members, and most of us were associate professors aged 40 to 50 . Only two female members took part in the conference in Istanbul. According to the special relational ethics involved in auto-ethnography (Ellis et al. 2011), which not only implicate my own personal experiences but also several others, I have tried to make my col-

leagues less identifiable, although they will be able to recognize themselves.

3. The full title is "Hamam: the Turkish Bath" (1997), directed by Ferzan Özpetek.

4. However, I did discuss my interpretation with several of the other participants while we were in Istanbul. And afterwards, I received comments on an earlier version of this article from some of the male participants, who are only discretely represented, according to the relational ethics required in auto-ethnography (Ellis et al. 2011)
5. This paper, by Carsten Bagge Laustsen and Bülent Diken, was most recently published as "Letters from the Turkish Bath: A Lacanian Approach to Orientalism" (2007). In Peripheral Insider. Perspectives on Contemporary Internationalism in Visual Culture. Copenhagen: Museum Tusculanum Press.

6. Retrospectively and from the perspective of what followed, it may seem rather naive that we thought this would work out smoothly. But this was the case and, because it was unexpected, probably one of the reasons why the experience came to matter so much.

7. Two academic participants, a secretary and the spouse of one of the male participants.

8 . Towels are obligatory pieces of clothing and covering in a hamam. But a female body needs more cloth than a male to cover up, and thus we needed two towels. The question of covering and enacting gender via towels is elaborated on later. 9. And probably also to test ourselves.

10. For a closer examination of the hamam and Orientalism, see Bagge Laustsen and Diken 2007.

References to the Orientalist understanding of a hamam were thus a key element in the concrete material-discursive configuration.

11. She further develops this point with a criticism of classic actor-network theory (as described first and foremost by Bruno Latour) for taking the manager's perspective.

12. Using Butler's terminology, one could say that I did not want to become an "abject" - neither subject nor object (Butler 1993).

\section{LITERATURE}

- Alaimo, Stacy \& Hekman, Susan (2008): Introduction: Emerging models of materiality in Feminist Theory, in: (Alaimo \& Hekman, eds.): Material Feminisms. Indiana University Press, Bloomington.

- Bagge Laustsen, Carsten \& Diken, Bülent (2007): Letters from the Turkish Bath: A Lacanian Approach to Orientalism, in: Khaled Ramadan (ed.): Peripheral Insider. Perspectives on Contemporary Internationalism in Visual Culture. Museum Tusculanum Press, Copenhagen.

- Barad, Karen (2003): Posthumanist Performativity: Towards an Understanding of How Matter Comes to Matter, in: Journal of Women in Culture and Society 2003; volume 28, number 3.

- Barad, Karen (2007): Meeting the Universe 
Halfway: Quantum Physics and the Entanglement of Matter and Meaning. Duke University Press, Durham.

- Butler, Judith (1990): Gender Trouble: Feminism and the Subversion of Identity. Routledge, New

York.

- Butler, Judith (1993): Bodies That Matter. On the Discursive Limits of "Sex". Routledge, New York. - Cussins, Charis (1996): Ontological Choreography, in: Social Studies of Science; volume 26: 575 610 .

· Ellingson, Laura L. \& Ellis, Carolyn (2008): Autoethnography as constructionist project, in: J.A. Holstein \& J.F. Gubrium (eds.): Handbook of Constructionist Research. Guilford Press, New York. - Ellis, Carolyn, Adams; Tony E. \& Bochner, Arthur P. (2011): Autoethnography: An Overview, in: Forum: Qualitative Social Research. Socialforshung. Volume 12, No.1.

- Said, Edward (1995 [1978]): Orientalism. Penguin Books, London.

- Star, Susan Leigh (1991): Power, technology and the phenomenology of conventions: on being allergic to onions, in: John Law (ed.): A Sociology of Monsters: Essays on Power, Technology and Domination. Sociological Review Monograph 38.

- Søndergaard, Dorthe Marie (1996) Tegnet på Kroppen. Køn, Koder og Konstruktioner blandt unge voksne i Akademia (The Sign on the Body. Gender, Codes and Constructions Among Young Adults in Academia). Museum Tusculanum Press, Copenhagen.

\section{SUMMARY}

This article seeks to develop a non-reductionist understanding that highlights how both material and discursive elements are involved in the doing of gender. It is presented as a piece of auto-ethnography, in which the author experienced how her own stabilised and neutral academic gender' suddenly became destabilised (and thus revealed to be material-discursive) when transferred to another material setting - specifically, a hamam in Istanbul. Although the author's social relationships with the male participants involved were unaltered, the gendered body came to matter in a new way when it was enacted or 'measured' in a different apparatus. Following the plot of this autoethnography, the article investigates how a performative approach could deal with materiality, moving from J. Butler's perspective and to a performative version of STS, particularly the concepts put forward by K. Barad.

Tine Damsholt, Associate Professor

in Ethnology

Saxo-Institute

University of Copenhagen 